\title{
Use of Community Health Support Workers for Persons Living With Human Immunodeficiency Virus in Rural Ethiopia: Lessons Learned
}

\author{
Alan R. Lifson ${ }^{1^{\star}}$, Sale Workneh ${ }^{2}$, Abera Hailemichael ${ }^{2}$, Workneh Demissie ${ }^{2}$, Lucy Slater ${ }^{3}$ and Tibebe Shenie ${ }^{2}$ \\ ${ }^{1}$ Division of Epidemiology and Community Health, University of Minnesota, Minneapolis, MN, USA \\ ${ }^{2}$ Ethiopian Office, National Alliance of State and Territorial AIDS Directors, Addis Ababa, Ethiopia \\ ${ }^{3}$ Global Program, National Alliance of State and Territorial AIDS Directors, Washington DC, USA
}

*Corresponding author: Alan Lifson, Division of Epidemiology and Community Health, University of Minnesota, 1300 S. Second Street, Suite 300 , Minneapolis, MN 55454-1015, USA, Tel: 612-626-9697; Fax: 612-624-0315; E-mail: lifso001@umn.edu

Copyright: (C) 2014 Lifson AR, et al. This is an open-access article distributed under the terms of the Creative Commons Attribution License, which permits unrestricted use, distribution, and reproduction in any medium, provided the original author and source are credited.

Received date: May 19, 2014; Accepted date: June 30, 2014; Published date: July 15, 2014

\begin{abstract}
Background: Health facilities in rural, resource limited settings face multiple challenges responding to a growing demand for HIV treatment, including lack of adequate numbers of trained health workers. Many programs have used community health support workers (CHSWs) to provide specific services related to HIV care, and to complement facility-based treatment.
\end{abstract}

Methods: In rural southern Ethiopia, 13 HIV-positive CHSWs were assigned to 142 newly diagnosed HIV patients from the same community to provide: education on HIV treatment and health promoting behaviors; counseling and social support; and linkage to the HIV Clinic.

Results: Lessons learned in planning and implementing CHSW programs for PLWH include the benefits of: involving local health bureaus, clinicians, and the community; careful recruitment processes and selection criteria for CHSWs; use of local PLWH as CHSWs to facilitate relationships with HIV-positive clients; initial and on-going training of CHSWs with didactic information and counseling skills; clearly defined responsibilities and regular, supportive supervision with constructive feedback; emphasizing importance of client confidentiality; and financial compensation for $\mathrm{CHSWs}$.

Conclusion: Use of CHSWs can be an effective strategy to support the HIV health care system, and offers a strong complement to facility-based care in rural and other resource-limited settings. However, such programs may be most successful if they attend to the multiple issues described above in planning and implementation.

Keywords: Human immunodeficiency virus; Community support workers; Rural health; Sub-saharan Africa

\section{Abbreviations \\ ART: Antiretroviral Therapy; CHSW: Community Health Support Worker; HIV: Human Immunodeficiency Virus; PLWH: People Living With HIV; SSA: Sub-Saharan Africa; WHO: World Health Organization}

\section{Background: HIV in Rural Africa}

Human immunodeficiency virus (HIV) is growing in rural areas, including in sub-Saharan Africa (SSA) [1-4]. In Ethiopia where $83 \%$ of the population is rural, over $37 \%$ of the estimated 1.2 million people living with HIV (PLWH) are in rural areas [5]. HIV prevalence in Ethiopia is increasing in small market towns compared to larger cities, with such towns potentially serving as bridging sites for urban to rural spread of HIV [6]. The number of HIV patients in rural facilities is also growing as programs promote decentralization of HIV care to peripheral health facilities [7-9]. In addition, many of those who become infected in urban settings return to their rural homes after they become ill, further increasing rural HIV health service demands [4].
Health facilities in rural settings face multiple challenges, including lack of adequate numbers of trained health workers [10-12]. To help address the shortage of trained health workers in resource-limited settings, many programs have used community health support workers (CHSWs) to provide specific health services related to HIV care, such as patient education, counseling, collection of clinical status data, and delivery of antiretroviral therapy (ART). Positive outcomes associated with CHSWs among HIV patients include ART adherence, viral suppression and overall survival [3,13-21]. Use of CHSWs also has beneficial results on loss to follow-up among HIV patients in care, including in rural settings $[13,15,18-21]$.

CHSWs are recognized as integral to primary health care in resource limited settings, including in rural areas, extending health care delivery, and complementing facility-based care [22-24]. One task force estimated that one million CHSWs should be trained and deployed in sub-Saharan Africa by 2015 to help meet primary care needs and Millennium Development Goals [23]. We describe lessons learned from developing and implementing a CHSW program for PLWH in rural Ethiopia, including suggestions for others considering similar programs. 
Citation: Lifson AR, Workneh S, Hailemichael A, Demissie W, Slater L, et al. (2014) Use of Community Health Support Workers for Persons Living With Human Immunodeficiency Virus in Rural Ethiopia: Lessons Learned. J AIDS Clin Res 5: 324. doi: $10.4172 / 2155-6113.1000324$

Page 2 of 4

\section{Description of a Community Support Worker Intervention for HIV Patients}

In rural Ethiopia, we developed an intervention to support treatment adherence and prevent default among HIV patients, using lay community members who were also PLWH. This project was conducted in Arba Minch, a rural town in the foothills of the Rift Valley in the Southern Nations, Nationalities, and Peoples' Region of Ethiopia. In addition to the town, many persons live in the surrounding villages, supporting themselves through farming.

The target population for this intervention was adult PLWH who were newly enrolled in HIV care within the past three months. Patients were recruited from the zonal referral hospital plus smaller health centers serving this area; those meeting inclusion criteria were sequentially offered enrollment. Of 142 participants in this project, $65 \%$ were female; the mean age was 34 years and the median CD4+ count at enrollment was 201 cells $/ \mathrm{mm}^{3}$. Thirty-five percent were classified as WHO Stage III or IV, and $75 \%$ had started on ART.

In Ethiopia, kebeles are small units of administration, representing neighborhoods (in cities or towns) or villages (in rural areas). Every resident of Ethiopia belongs to a kebele, which provides many basic municipal services. From each kebele where an HIV patient was enrolled, a CHSW from the same area of residence was selected to work with that client. Thirteen CHSWs provided services for up to 20 clients each. CHSWs visited clients 1-4 times/month; the average total time spent with each client was 2-3 hours per month.

CHSW responsibilities were as follows: (1) education on HIV treatment (including ART side effects) and health promoting behaviors (including nutrition); (2) counseling and social support (including helping clients address negative personal feelings about being HIV-positive and disclosure of HIV status to others); and (3) facilitating linkage and engagement with the HIV Clinic. CHSWs were given cell phones to call a designated HIV Clinic nurse, including for questions about new medical symptoms or changes in clinical status in clients. CHSWs also provided referrals to local PLWH associations and other organizations that could help meet client needs such as nutrition, clothing, and development of income-generating activities.

\section{Results and Discussion: Lessons Learned}

\section{Consultation with multiple stakeholders}

This program was developed after discussions with and advice from health bureau staff at the local and regional levels, HIV clinicians, kebele and other community leaders, and PLWH associations. We believe that prior involvement of these various important stakeholders and partners contributed to the positive collaboration and support that CHSWs received from multiple sectors.In planning CHSW programs, we emphasize the importance of community participation and engagement of key stakeholders, including public health bureaus and clinical care providers [22,25-28].

\section{Selection of CHSWs}

Careful recruitment processes and selection criteria for CHSWs are important; belonging to the community they will be working in and motivation to serve that community are important considerations [22,25-29]. In this project, position announcements were posted in the kebeles included in our program area, as well as on Arba Minch Hospital notice boards. As part of the interview, applicants were presented with case situations potentially affecting PLWH, and asked how they might address them.Evaluation criteria included previous training and work experience (paid or volunteer), plus demonstrated maturity, good communication skills, sensitivity and expressed commitment towards working with PLWH. Strong preference was given to applicants who were PLWH themselves.

Out of 27 interviewees, 20 were selected for participation in an initial one-week training (detailed below). During this training, participants were observed for personal skills described above. Based upon this observation, plus performance on a post-training knowledge test, a final group of 13 CHSWs (8 women and five men) were chosen; this final group included persons from both Arba Minch town and local villages, representing all of the kebeles in our project area.

\section{Use of PLWH as CHSWs}

In this support program for HIV patients, the fact that CHSWs were PLWH and members of the same communities as their clients was valuable in facilitating client relationships and acceptance. Social support as coping assistance may be strengthened when it comes from those who have faced similar stressors and life circumstances, and have been able to effectively manage these challenges [30].A number of clients expressed feelings that their CHSW was a supportive and accepting partner, who as another PLWH could understand a client's personal experiences and challenges. Many CHSWs reported the personal satisfaction of knowing that through this project they were benefiting others in their community, in particular PLWH. Several CHSWs reported that through participation in this project they became more comfortable with their own HIV status, allowing them to reflect back to their clients a positive and confident model of someone living with HIV.Other programs also describe positive aspects of using PLWH to provide care and support services to other HIV-positive persons $[13,31,32]$.

\section{Training}

We emphasize, as others have done, the importance of CHSWs receiving initial and on-going training [22,25-29,32]. The schedule for the initial one-week training is detailed in the Appendix, and contained both didactic information and counseling skills. This initial training included talks on: HIV transmission, clinical outcome, and monitoring; ART regimens, side effects, and adherence; nutrition and other health promoting behaviors; and counseling skills, using approaches that were supportive, accepting and empathic. Group exercises included practice counseling sessions and role-playing. Training was primarily conducted by the coauthors on this manuscript, with additional participation from HIV clinicians at Arba Minch Hospital and a nutrition specialist at Arba Minch University.

Training updates for CHSWs were provided several ways. During their monthly group meetings (described below), CHSWs received from the HIV Clinic Nurse short talks on various topics related to HIV health, such as sanitation or proper food preparation. In addition, during his quarterly monitoring visits, the Project Director (Dr. Lifson) would present a lecture on some topic of interest requested by the CHSW group, such as tuberculosis or other co-infections. One year after the initial training, a one-day refresher training was also held for CHSWs, to provide updated information on many topics covered in the initial course.

Increasing their HIV disease knowledge and counseling skills helped CHSWs to most effectively support their clients, and ongoing 
Citation: Lifson AR, Workneh S, Hailemichael A, Demissie W, Slater L, et al. (2014) Use of Community Health Support Workers for Persons Living With Human Immunodeficiency Virus in Rural Ethiopia: Lessons Learned. J AIDS Clin Res 5: 324. doi: $10.4172 / 2155-6113.1000324$

Page 3 of 4

training helped to reinforce initially presented information and skills. As an additional benefit, some CHSWs reported that by learning more about HIV and its treatment, they were able to better manage their own HIV infection.

\section{Supervision}

We emphasize the importance of CHSWs having clearly defined responsibilities, regular and reliable supportive supervision, and constructive feedback [22,25-29]. A project coordinator was hired for this study to supervise CHSWs. CHSWs were required to fill out encounter forms for each visit with each client; CHSWs recorded on these forms the date and time spent for each contact and a brief description of what was discussed or decided. Forms were turned in each month, allowing the project coordinator to monitor work performance and to address any problems in a timely fashion. In addition, the project coordinator met monthly with CHSWs as a group, where they shared experiences, strategies and lessons learned in working with clients; this allowed CHSWs to advise each other and to provide recommendations to improve the project. Meeting as a group fostered a sense of group identity and mutual support among CHSWs, contributing to their dedication to this project.

Importantly, although CHSWs in this program had clear accountability, they also had a certain flexibility to use their experience and best judgment in responding to individual client needs and circumstances. We believe that not only did this contribute to CHSW motivation, but also provided the best model for collaborative care.

\section{Confidentiality}

Breach of confidentiality could occur if a CHSW revealed to someone outside the project information reported by a client, or even that the client was HIV-positive. Training and supervision for CHSWs stressed the importance of participant confidentiality, especially given the stigma that many PLWH face in their communities [33,34]. Maintenance of confidentiality is critical to the client-CHSW trust relationship; CHSWs were told that breach of confidentiality is an offense for which there would be minimal tolerance, with likely removal from the project. No such offenses were reported.

\section{Financial compensation}

We emphasize, as others have done, that CHSWs should receive adequate remuneration [22,25-29]. Lack of payment and reliance on voluntarism is a cause of attrition among CHSWs, and a disincentive to spending significant amounts of time on program activities $[25-27,29,35]$. CHSWs in this project received modest but very important financial support for their time and effort, with a monthly allowance of 700 Ethiopian birr ( $\sim 37$ U.S.).CHSWs expressed pride that they were able to financially support themselves and contribute to their families, and felt that this financial support allowed them to fully participate in this project.

\section{Conclusion}

If CHSW programs are to be successfully integrated into the HIV care system, sustainability will be critical. Ethiopia has implemented a nationwide program of health extension workers recruited from their prospective villages to provide basic health services [36], and we believe that training and implementation of a program using "specialist community health workers" [26] can be integrated into this system to address specific health issues for PLWH. Education and social support needs for PLWH are likely to be greatest for those who are newly diagnosed; treatment default for ART patients tends to be greatest within the first year after enrollment in care [37].As patients become more informed and accepting of their status, the frequency and intensity of CHSW support needs would be expected to decline.

Our experience suggests that CHSWs programs may be most successful if they include involvement and support from multiple stakeholders (including the community, clinical providers, and public health officials), plus specific procedures for CHSW selection, training, supervision and financial support. For HIV patients, CHSWs who are also PLWH can be particularly effective. If adequately designed and implemented, with careful attention to the issues described in this manuscript, deployment of CHSWs can be an effective strategy to support the health care system for PLWH, offering a strong complement to facility-based care in rural resource-limited and other settings.

\section{Acknowledgements}

Funding for this project was provided by the University of Minnesota's Office for International Programs. We wish to thank the following individuals and organizations who provided technical advice, support, or assistance: the Southern Nations, Nationalities, and People's Regional Health Bureau; the GamoGofa zonal health department; Arba Minch Hospital; the Arba Minch zuria woreda health office; the Arba Minch town health office; the Arba Minch Health Center; the Arba Minch NGO forum (including local PLWH associations), Gezie Aba and Randy May from the National Alliance for State and Territorial AIDS Directors.

\section{References}

1. Wilson DP, Blower S (2007) How far will we need to go to reach HIVinfected people in rural South Africa? BMC Med 5: 16.

2. Van Rompaey S, Kimfuta J, Kimbondo P, Monn C, Buvé A (2011) Operational assessment of access to ART in rural Africa: the example of Kisantu in Democratic Republic of the Congo. AIDS Care 23: 686-693.

3. Kipp W, Konde-Lule J, Saunders LD, Alibhai A, Houston S, et al. (2012) Antiretroviral treatment for HIV in rural Uganda: two-year treatment outcomes of a prospective health centre/community-based and hospitalbased cohort. PLoS One 7: e40902.

4. Oramasionwu CU, Daniels KR, Labreche MJ, Frei CR (2011) The environmental and social influences of HIV/AIDS in sub-Saharan Africa: a focus on rural communities. Int J Environ Res Public Health 8: 2967-2979.

5. Ethiopian National AIDS Resource Center (2010) National Factsheet (2010).

6. Federal Democratic Republic of Ethiopia (2012) Country Progress Report on HIV/AIDS Response (2012).

7. World Health Organization (2013) Consolidated guidelines on the use of antiretroviral drugs for treating and preventing HIV infection: Recommendations for a public health approach.

8. Federal HIV/AIDS Prevention and Control Office, Federal Ministry of Health (2010) Strategic Plan II for Intensifying Multisectoral HIV and AIDS Response in Ethiopia, 2010/11 - 2014/15.

9. Chan AK, Mateyu G, Jahn A, Schouten E, Arora P, et al. (2010) Outcome assessment of decentralization of antiretroviral therapy provision in a rural district of Malawi using an integrated primary care model. Trop Med Int Health 15 Suppl 1: 90-97.

10. World Health Organization (2006) The world health report 2006: working together for health. 
Citation: Lifson AR, Workneh S, Hailemichael A, Demissie W, Slater L, et al. (2014) Use of Community Health Support Workers for Persons Living With Human Immunodeficiency Virus in Rural Ethiopia: Lessons Learned. J AIDS Clin Res 5: 324. doi: $10.4172 / 2155-6113.1000324$

Page 4 of 4

11. Rasschaert F, Philips M, Van Leemput L, Assefa Y, Schouten E, et al. (2011) Tackling health workforce shortages during antiretroviral treatment scale-up--experiences from Ethiopia and Malawi. J Acquir Immune DeficSyndr 57: S109-112.

12. Hirschhorn LR, Oguda L, Fullem A, Dreesch N, Wilson P (2006) Estimating health workforce needs for antiretroviral therapy in resourcelimited settings. Hum Resour Health 4: 1.

13. Bekker LG, Myer L, Orrell C, Lawn S, Wood R (2006) Rapid scale-up of a community-based HIV treatment service: programme performance over 3 consecutive years in Guguletu, South Africa. S Afr Med J 96: 315-320.

14. Weidle PJ, Wamai N, Solberg P, Liechty C, Sendagala S, et al. (2006) Adherence to antiretroviral therapy in a home-based AIDS care programme in rural Uganda. Lancet 368: 1587-1594.

15. Fatti G, Meintjes G, Shea J, Eley B, Grimwood A (2012) Improved survival and antiretroviral treatment outcomes in adults receiving community-based adherence support: 5-year results from a multicentre cohort study in South Africa. J Acquir Immune DeficSyndr 61: e50-58.

16. Kabore I, Bloem J, Etheredge G, Obiero W, Wanless S, et al. (2010) The effect of community-based support services on clinical efficacy and health-related quality of life in HIV/AIDS patients in resource-limited settings in sub-Saharan Africa. AIDS Patient Care STDS 24: 581-594.

17. Kipp W, Konde-Lule J, Rubaale T, Okech-Ojony J, Alibhai A, et al. (2011) Comparing antiretroviral treatment outcomes between a prospective community-based and hospital-based cohort of HIV patients in rural Uganda. BMC Int Health Hum Rights 11: S12.

18. Mwai GW, Mburu G, Torpey K, Frost P, Ford N, et al. (2013) Role and outcomes of community health workers in HIV care in sub-Saharan Africa: a systematic review. J Int AIDS Soc 16: 18586.

19. Cohen R, Lynch S, Bygrave H, Eggers E, Vlahakis N, et al. (2009) Antiretroviral treatment outcomes from a nurse-driven, communitysupported HIV/AIDS treatment programme in rural Lesotho: observational cohort assessment at two years. J Int AIDS Soc 12: 23.

20. Jaffar S, Amuron B, Foster S, Birungi J, Levin J, et al. (2009) Rates of virological failure in patients treated in a home-based versus a facilitybased HIV-care model in Jinja, southeast Uganda: a cluster-randomised equivalence trial. Lancet 374: 2080-2089.

21. Franke MF, Kaigamba F, Socci AR, Hakizamungu M, Patel A, et al. (2013) Improved retention associated with community-based accompaniment for antiretroviral therapy delivery in rural Rwanda. Clin Infect Dis 56: 1319-1326.

22. World Health Organization (2010) Global experience of community health workers for delivery of health related millennium development goals: A systematic review, country case studies, and recommendations for integration into national health systems.

23. Singh P, Sachs JD (2013) 1 million community health workers in subSaharan Africa by 2015. Lancet 382: 363-365.

24. McCord GC, Liu A, Singh P (2013) Deployment of community health workers across rural sub-Saharan Africa: financial considerations and operational assumptions. Bull World Health Organ 91: 244-253B.
25. Celletti F, Wright A, Palen J, Frehywot S, Markus A, et al. (2010) Can the deployment of community health workers for the delivery of HIV services represent an effective and sustainable response to health workforce shortages? Results of a multicountry study. AIDS 24 Suppl 1: S45-57.

26. Lehmann U, Sanders D (2007) Community health workers: What do we know about them? The state of the evidence on programmes, activities, costs and impact on health outcomes of using community health workers. World Health Organization.

27. Bhattacharyya K, Winch P, LeBan K, Tien M (2001) Community health worker incentives and disincentives: how they affect motivation, retention, and sustainability. Basic Support for Institutionalizing Child Survival Project (BASICS II) for United States Agency for International Development.

28. Crigler L, Hill K, Furth R, Bjerregaard D (2013) Community Health Worker Assessment and Improvement Matrix (CHW AIM): A toolkit for improving $\mathrm{CHW}$ programs and services. USAID Health Care Improvement Project.

29. Hermann K, Van Damme W, Pariyo GW, Schouten E, Assefa Y, et al. (2009) Community health workers for ART in sub-Saharan Africa: learning from experience--capitalizing on new opportunities. Hum Resour Health 7: 31.

30. Thoits PA (1986) Social support as coping assistance. J Consult ClinPsychol 54: 416-423.

31. Chang LW, Kagaayi J, Nakigozi G, Ssempijja V, Packer AH, et al. (2010) Effect of peer health workers on AIDS care in Rakai, Uganda: a clusterrandomized trial. PLoS One 5: e10923.

32. Wools-Kaloustian KK, Sidle JE, Selke HM, Vedanthan R, Kemboi EK, et al. (2009) A model for extending antiretroviral care beyond the rural health centre. J Int AIDS Soc 12: 22.

33. Lifson AR, Demissie W, Tadesse A, Ketema K, May R, et al. (2012) HIV/ AIDS stigma-associated attitudes in a rural Ethiopian community: characteristics, correlation with HIV knowledge and other factors, and implications for community intervention. BMC Int Health Hum Rights 12: 6 .

34. Mbonu NC, van den Borne B, De Vries NK (2009) Stigma of People with HIV/AIDS in Sub-Saharan Africa: A Literature Review. J Trop Med 2009: 145891.

35. Philips M, Zachariah R, Venis S (2008) Task shifting for antiretroviral treatment delivery in sub-Saharan Africa: not a panacea. Lancet 371: 682-684.

36. Teklehaimanot HD, Teklehaimanot A (2013) Human resource development for a community-based health extension program: a case study from Ethiopia. Hum Resour Health 11: 39.

37. Fox MP, Rosen S (2010) Patient retention in antiretroviral therapy programs up to three years on treatment in sub-Saharan Africa, 2007-2009: systematic review. Trop Med Int Health 15 Suppl 1: 1-15. 